\title{
INNOVATION IN GREEN PROCESS ENGINEERING UNDERGRADUATE LABORATORY COURSE - INTEGRATED LABORATORIES FOR PARTICULATE OPERATIONS, HEAT TRANSFER AND MASS TRANSFER COURSES
}

\author{
Chunbao (Charles) Xu*, L. Sang, D. Bao, H. Siddiqui, K. Abbott, V. Balasundharam, J. Chad, Z. Freeman, J. C. Vanegas, \\ E. Maddox, C. Piccolo, J. Ward, C. Wu, D. Xiang, K. Young \\ Green Process Engineering Program, Department of Chemical and Biochemical Engineering, Western University, London, \\ ON, N6A 5B9 \\ *Correponding author: cxu6@uwo.ca
}

\begin{abstract}
In the past two years since 2011, the course instructor (Dr. Xu), along with the students in the Green Process Engineering (GPE) class and TAs, has developed an innovative undergraduate laboratory course that integrates laboratories for particulate operations, heat and mass transfer courses. The integrated lab course runs as research projects that apply and integrate the concepts reviewed in the above courses. One of the key objectives of this course is to train team work and leadership. To this end, the students are grouped into 4 groups, and each group carries out one of the following 4 projects for $6 \mathrm{~h} /$ week and approx. 6 weeks, rotates the projects and completes all by the end of this full-year course: (1) Particulate operations heterogeneous catalyst particles $\left(\mathrm{Au} / \mathrm{MgAl}_{2} \mathrm{O}_{4}\right)$ formation, handling and characterization; (2) Convective heat transfer enhancement in a stirred tank reactor; (3) Liquid phase mass transfer in a gas-liquid stirred reactor system; (4) A green process for the production of acetic acid via aqueous phase oxidation of ethanol with air using $\mathrm{Au} / \mathrm{MgAl}_{2} \mathrm{O}_{4}$ catalyst: effects of mass transfer and reaction kinetics. As the course learning objectives, students should be able to propose experimental methodologies and design their own experimental procedure, secure and prepare their own experimental materials and equipment and facilities, perform the experiments and collect data, interpret the experimental results using the principles and knowledge from the relevant courses, and present their results effectively.
\end{abstract}

Keywords: Green Process Engineering Program; Undergraduate laboratory course; Integrated laboratories; Particulate operations; Heat transfer;

Mass transfer; Reaction engineering.

\section{INTRODUCTION OF THE GPE LABORATORY COURSE AT WESTERN UNIVERSITY}

\subsection{The Green Process Engineering (GPE) Program at Western University}

Western's Green Process Engineering (GPE) Program is a new undergraduate program, the first of its kind in Canada. It was established in 2009 and received accreditation in 2012 from CEAB. The program is considered unique as it combines and integrates the fundamental principles of chemical engineering and environmental engineering to design commercial products and processes that are inherently clean and sustainable, safe, economical and environmentally friendly. There are three options for students in the program:

1) Green Process Engineering (regular BESc, 4 years including the common 1st year).

2) Green Process Engineering with Management (BESc/HBA in 5 years)

3) Green Process Engineering with Law (BESc/JD in 6 years)

Graduates of the Green Process Engineering program will have employment opportunities in broad-based areas such as biofuels, bio-products, green power, and green chemical products and processing industries [1].

\subsection{Course Leaning Objectives}

Design and perform laboratory-based experiments related to Green Process Engineering and interpret their results, using the principles and knowledge from the following courses and topics:

$\begin{array}{ll}\circ & \text { Heat transfer operations (GPE 3322) } \\ \circ & \text { Mass transfer operations (GPE 3324) } \\ \circ & \text { Particulate operations (GPE 3325) } \\ \circ & \text { Chemical reaction engineering } \\ & \text { (particularly catalytic reaction engineering) }\end{array}$

Generally, students should be able to:

- Propose experimental methodologies and design their own experimental procedure.

- Secure and prepare their own experimental materials and equipment and facilities, with the 
assistance of the instructor, lab technicians and teaching assistants (TAs).

- Perform the experiments and collect data

- Interpret the experimental results using the principles and knowledge from the relevant courses.

- Present their results and conclusions in a clear, concise and effective manner.

\subsection{Format of the Course}

This laboratory course is offered in the form of green engineering projects that apply and integrate the concepts reviewed in heat and mass transfer operations, and particulate operations courses. Training of team work and leadership is one of the key objectives of this course, the projects are all group projects involving 2-5 students depending on the size of the class. For the purpose of training, the students are expected to spend 6h/week for approximately 26 weeks (two semesters) working on their projects using equipment that is available in the GPE Laboratory.

The students are grouped into 4 groups and all the groups will carry out one of the following 4 projects (6 weeks per project in an average). The groups will rotate the projects and will complete all projects (lab sessions) by the end of this Lab course (in Winter term).

- Project \#1: Particulate operations heterogeneous catalyst particles formation, handling and characterization

- Project \#2: Convective heat transfer enhancement in a stirred tank reactor involving solid particles

- $\quad$ Project \#3: Liquid phase mass transfer in a gas-liquid stirred reactor system

- Project \#4: A green process for the production of acetic acid via aqueous phase oxidation of ethanol with air using $\mathrm{Au} / \mathrm{MgAl}_{2} \mathrm{O}_{4}$ catalyst: effects of mass transfer and reaction kinetics

The performance of the students for this course will be evaluated according to the following criteria: (1) Amount of time spent in the project (experimental work in the lab, results analysis/ reporting), (2) Judgment, (3) Individual and team work, (4) Quality and amount of the data from the experimental labs, and (5) Quality of the analysis/discussion of the results, relating the results with the concepts reviewed in the relevant courses. The final grade for each student will be given based on the marks received from the following assessment components: (1) Proposals of experimental plan and procedure $(30 \%)$, (2) Efforts in carrying out the experiments (10\%), (3) Project reports (on results/discussion/conclusions) (45\%), and (5) Oral presentations (at the end of each term) (15\%).

\section{INTRODUCTION OF THE LABORATORIES AND PROJECTS}

\subsection{Project \#1: Particulate Operations - Heterogeneous Catalyst Particles Formation, Handling and Characterization}

2.1.1 Project Objectives. At the end of this project, students should be able to:

(1) Synthesize $8.0 \mathrm{~g} \mathrm{MgAl}_{2} \mathrm{O}_{4}$ particulate materials (precipitation synthesis, centrifugal separation, drying, calcination, crushing, sieving), with an average particle size of $<300 \mu \mathrm{m}$;

(2) Load Au metal on the support (impregnation, evaporation, calcination, crushing, sieving) to make $5.0 \mathrm{~g}$ supported metal catalysts of $1 \mathrm{wt} \% \mathrm{Au} / \mathrm{MgAl}_{2} \mathrm{O}_{4}$;

(3) Characterize/analyze the fresh $1 \mathrm{wt} \% \mathrm{Au} / \mathrm{MgAl}_{2} \mathrm{O}_{4}$ catalyst (surface area, $\mathrm{XRD}$, SEM-EDX, etc.)

2.1.2 Relevance and Significance. Catalyst promotes the rate of a chemical reaction the reaction by reducing its activation energy. As listed below, catalysis is one of the twelve principles of green chemistry.

$\begin{array}{ll}\square & \text { Prevention } \\ \square & \text { Atom Economy } \\ \square & \text { Less Hazardous Chemical Syntheses } \\ \square & \text { Designing Safer Chemicals } \\ \square & \text { Safer Solvents and Auxiliaries } \\ \square & \text { Design for Energy Efficiency } \\ \square & \text { Use of Renewable Feedstock } \\ \square & \text { Reduce Derivatives } \\ \square & \text { Catalysis } \\ \square & \text { Design for Degradation } \\ \square & \text { Real-time Analysis for Pollution Prevention } \\ \square & \text { Inherently Safer Chemistry for Accident } \\ & \text { Prevention }\end{array}$

Heterogeneous catalysis refers to the form of catalysis where the phase of the catalyst differs from that of the reactants. The great majority of practical heterogeneous catalysts are solids and the great majority of reactants are gases or liquids. An advantage of using heterogeneous catalysts is their ease of separation from the reactants and products. An example of the heterogeneous catalyst is the alumina-supported nickel catalyst $\left(\mathrm{Ni} / \mathrm{Al}_{2} \mathrm{O}_{3}\right)$ for the methane-steam reforming reaction to produce hydrogen gas from natural gas:

$$
\mathrm{CH}_{4}+\mathrm{H}_{2} \mathrm{O} \stackrel{\mathrm{Ni} \mathrm{Al}_{2} \mathrm{O}_{3}}{\longrightarrow} \mathrm{CO}+3 \mathrm{H}_{2}
$$

Heterogeneous catalysis is of paramount importance in many areas of the chemical and energy industries, in particular the petrochemical industry. The petroleum refinery industry is the largest single user of catalysts, especially in the processes of Fluid Catalytic Cracking (FCC) to produce refined products such as gasoline and 
diesel fuels, Hydro-Processing (hydro-treating and hydrocracking for desulfurization, denitrogenation and demetallization, and upgrading of bitumen/heavy oils), and Reforming or Isomerization to upgrade the octane number of gasoline. Catalysts are indispensable to many other chemical and environmental processes from chemical synthesis to vehicle emissions control systems. The global market for energy and environmental catalysts was worth an estimated $\$ 6.4$ billion in 2003 , $\$ 13.0$ billion in 2009 , and the market was projected to grow at an average annual growth rate of $12.8 \%$ [2].

2.1.3 Theory/Background. Production of supported heterogeneous catalysts involving preparation of particulate materials as catalyst support and loading active components (metals or metal oxides) on the support materials. The key unit operations for bulk catalyst and support preparation are listed in Table 1.

Table 1: Key unit operations for bulk catalyst and support preparation.

\begin{tabular}{|l|l|}
\hline 1. Precipitation & 7. Calcination \\
\hline 2. Gelation & 8. Forming operation \\
\hline $\begin{array}{l}\text { 3. Hydrothermal } \\
\text { transformation }\end{array}$ & 9. Impregnation \\
\hline $\begin{array}{l}\text { 4. Decantation, filtration and } \\
\text { centrifugation }\end{array}$ & 10. Crushing and grinding \\
\hline 5. Washing & 11. Mixing \\
\hline 6. Drying & 12. Activation \\
\hline
\end{tabular}

Some most important unit operation steps are described below:

Precipitation. The aim of this step is to precipitate a solid from a liquid solution containing the precursor compound(s). Normally a precursor compound is dissolved in water and then it is precipitated by adding a basic solution (such as concentrated ammonia solution or $\mathrm{NaOH}$ solution, etc.). Example precipitation reaction is shown as follows:

\section{$\mathrm{Mg}\left(\mathrm{NO}_{3}\right)_{2} \cdot 5 \mathrm{H}_{2} \mathrm{O}+2 \mathrm{NH}_{4} \mathrm{OH} \rightarrow \mathrm{Mg}(\mathrm{OH})_{2} \downarrow+2$ $\mathrm{NH}_{4} \mathrm{NO}_{3}+5 \mathrm{H}_{2} \mathrm{O}$}

Co-precipitation is employed to prepare a complex compound containing two and more components such as $\mathrm{MgAl}_{2} \mathrm{O}_{4}$ for this project. During co-precipitation care must be taken in order to avoid independent or consecutive precipitations. Besides, the $\mathrm{pH}$ should be adjusted and kept constant during the operation: this can be done by mixing the starting solution continuously, instead of adding one solution to the other.

Calcination. After decantation, filtration, centrifugation and drying, the particles need to be calcinated (usually in air at high temperatures $>500^{\circ} \mathrm{C}$ ) in order to convert the precursors into metal oxides and stabilize the mechanical properties of the particles. Calcination is typically at temperatures higher than those used in the catalytic reaction and catalyst regeneration. Other thermal treatments, such as reductions or sulfidations, are performed in special atmospheres, so they will be designated as activation operations. Several processes occur during calcination: loss of the chemically bonded water or $\mathrm{CO}$, modification of the texture through sintering (small crystals or particles which turn into bigger ones), modification of the structure, active phase generation and stabilization of mechanical properties.

Impregnation. Impregnation as a means of supported catalyst preparation is achieved by filling the pores of a support with a solution of the metal salt(s) from which the solvent is subsequently evaporated. The catalyst is prepared either by spraying the support with a solution of the metal compound(s) or by adding the support material to a solution of a suitable metal salt(s), such that the required weight of the active components are incorporated into the support without the use of excess of solution. This is then followed by drying and subsequent decomposition of the salt(s) at an elevated temperature (activation process), either by thermal decomposition (i.e., calcination) or reduction

2.1.4 Synthesis of Nanocrystallite $1 \mathrm{wt} \% \mathrm{Au} / \mathrm{MgAl}_{2} \mathrm{O}_{4}$ catalyst. As introduced in the literature by Salmones et al. [3], $\mathrm{MgAl}_{2} \mathrm{O}_{4}$, is widely applied as ceramic materials due to its high melting point, good chemical stability and mechanical strength. Recently, there has been growing interest in the utilization of $\mathrm{MgAl}_{2} \mathrm{O}_{4}$ as catalysts or catalysts support in the fields of environmental catalysis, petroleum processing and fine chemicals production. This project aims to produce 5.0 $\mathrm{g}$ heterogeneous supported catalyst $1 \mathrm{wt} \% \mathrm{Au} / \mathrm{MgAl}_{2} \mathrm{O}_{4}$ to be used in Project \#4 for the production of acetic acid via aqueous phase oxidation of ethanol with air:

$$
\begin{aligned}
& \mathrm{CH}_{3} \mathrm{CH}_{2} \mathrm{OH}+\mathrm{O}_{2} \rightarrow \mathrm{CH}_{3} \mathrm{COOH}+\mathrm{H}_{2} \mathrm{O} \\
& \Delta \mathrm{H}_{298}^{\circ}=-448.6 \mathrm{~kJ} / \mathrm{mol}
\end{aligned}
$$

The supported catalyst $\mathrm{Au} / \mathrm{MgAl}_{2} \mathrm{O}_{4}$ will be prepared with impregnation method to deposit an Au compound $\left(\mathrm{HAuCl}_{4} \cdot 3 \mathrm{H}_{2} \mathrm{O}\right)$ to $\mathrm{MgAl}_{2} \mathrm{O}_{4}$ particles as the catalyst support. We target to synthesize around $8 \mathrm{~g} \mathrm{MgAl}_{2} \mathrm{O}_{4}$ support in this project with the precipitation method using compounds of $\mathrm{Mg}\left(\mathrm{NO}_{3}\right)_{2} \cdot 6 \mathrm{H}_{2} \mathrm{O}$ and $\mathrm{Al}\left(\mathrm{NO}_{3}\right)_{3} \cdot 9 \mathrm{H}_{2} \mathrm{O}$ as precursors. The co-precipitation method for synthesis of nanocrystallite $\mathrm{MgAl}_{2} \mathrm{O}_{4}$ spinels as catalysts support was described in the literature $[3,4]$.

With the $\mathrm{MgAl}_{2} \mathrm{O}_{4}$ support prepared, the students are required to synthesize approx. $5 \mathrm{~g}$ supported catalyst $1 \mathrm{wt} \%$ $\mathrm{Au} / \mathrm{MgAl}_{2} \mathrm{O}_{4}$ using impregnation method with $\mathrm{HAuCl}_{4} \cdot 3 \mathrm{H}_{2} \mathrm{O}$ salt. The impregnated catalyst particles 
are calcinated at $1000^{\circ} \mathrm{C}$ in air for $3 \mathrm{~h}$ in a furnace, followed by crushing to $<300 \mu \mathrm{m}$.

\subsection{Project \#2: Convective Heat Transfer Enhancement in a Stirred Tank Reactor Involving Solid Particles}

\subsubsection{Project Objectives. At the end of this project,} students should be able to:

(1) Experimentally measure convective heat transfer coefficients in a stirred tank reactor involving solid particles;

(2) Study the effects of stirring speed, solid particle concentration on convective heat transfer coefficients in the reactor.

2.2.2 Relevance and Significance. CSTR (Continuous Stirred-Tank Reactor) is one of the most common reactors in a variety of industrial applications in the sectors of foods, pharmaceuticals, polymers, bio-fuels, and chemicals production. An application of CSTR reactor can be found in biodiesel production from vegetable oils via transesterification reaction with methanol, catalyzed by an acid or a base. Biodiesel has cleaner combustion, faster biodegradation, and minimal emissions compared to petro-diesel. This makes biodiesel a viable candidate to replace current petrodiesel fuel. Industrial production of biodiesel is commonly carried out in a CSTR using a homogeneous catalyst (i.e., $\mathrm{NaOH}$ ) that is not reusable and results in large quantities of wastewater from the product washing stages to remove the catalyst. Side reactions, like saponification, also occur when using homogeneous $\mathrm{NaOH}$ catalyst and make the process less environmentally friendly while negatively impacting product quality and yield. A solution to these problems is the use of strong solid acid/base catalysts [5,6]. Example of solid acid/base catalysts are sulfated zirconia, $\mathrm{MgO}$ and $\mathrm{CaO}$, etc. One of the major advantages of using a solid catalyst is that it is safe and non-corrosive and it eliminates the water washing step, which would be more economical and environmentally benign. The biodiesel synthesis process is normally kept just above the boiling point of the alcohol (around $70^{\circ} \mathrm{C}$, $158^{\circ} \mathrm{F}$ ) to speed up the reaction. According to reaction kinetics, the reaction rate would double by increasing the temperature by $10^{\circ} \mathrm{C}$. The presence of a solid catalyst not only promotes the reaction, but also affect (positively or negatively, depending on the relative heat capacities of the solid particles to that of the fluid in the reactor) the heat and mass transfer in the reactor system, and hence influence the overall reaction rate.

In this project, we will design experiments to measure the global heat transfer coefficients in a stirred tank reactor involving solid particles, and study the effects of stirring speed, and concentration of the solid particles in the slurry on heat transfer coefficients in the reactor.

2.1.3 Theory/Background. For a stirred tank reactor system for heat transfer studies (Fig. 1), we can assume the following parameters:

- The water bath temperature is $T_{\mathrm{w}}$, set and controlled by the hot plate stirrer;

- Room air temperature is $T_{\mathrm{a}}$, measured separated;

- The initial temperature of the water slurry before being immersed into the heated water bath is $T_{0}$,

- The temperature of the water slurry (water + solid particles) inside the flask (reactor) is $T$, measured and monitored with a digital thermometer;

- $\mathrm{A}_{1}=$ Area of the flask external surface wetted by the bath water

- $\mathrm{A}_{2}=$ (Area of the flask internal surface wetted by the slurry) - (Area of the flask external surface wetted by the bath water)

- NOTE: The amount (or level) of water in the water bath must be kept the same for all tests, which then make $A_{1}$ and $A_{2}$ constant in all tests.

- The global heat transfer efficiency on the surface of $A_{1}$ is $U_{1}\left(\mathrm{~W} / \mathrm{m}^{2} / K\right)$. $U_{1}$ is mainly determined by the forced convective heat transfer efficiency between the slurry inside the flask and the heat source (water in the bath);

- The global heat transfer efficiency on the surface of $A_{2}$ is $U_{2}\left(\mathrm{~W} / \mathrm{m}^{2} / \mathrm{K}\right) . \mathrm{U}_{2}$ is mainly attributed to the natural convective heat transfer between the slurry inside the flask and the environment (air);

- The heat loss from the flask's unwetted surface and the top surface of the slurry in the flask is negligible.

Figure 1 illustrates the heat balance of the stirred tank reactor with slurry of water-solid particles heated in a water bath at $T_{\mathrm{w}}$. The unsteady state heat balance equation at any given time $\theta$ after immersing the flask into the heated water bath (kept at $T_{\mathrm{w}}$ ) can be written as follows:

\{Slurry net heat accumulation $\}=$

$\{$ Heat transferred from the water bath $\}-\{$ Heat loss to the environment $\}$

$m C_{p, m} \frac{d T}{d \theta}=A_{1} U_{1}\left(T_{w}-T\right)-A_{2} U_{2}\left(T-T_{a}\right)$

where, $m$ is the total mass of the slurry: $m=m_{\text {water }}+$ $m_{\text {solids }} ; C_{\mathrm{p}, \mathrm{m}}$ is the weighed average heat capacity of the slurry, given the heat capacity of water the solid particles is $C_{\mathrm{p} \text {,water }}$ and $C_{\mathrm{p} \text {,solids }}$, respectively.

Rearrange Eq. (1) to:

$m C_{p, m} \frac{d T}{d \theta}=\left(-A_{1} U_{1}-A_{2} U_{2}\right) T+A_{1} U_{1} T_{w}+A_{2} U_{2} T_{a}$

$\frac{d T}{\left(-A_{1} U_{1}-A_{2} U_{2}\right) T+A_{1} U_{1} T_{w}+A_{2} U_{2} T_{a}}=\frac{1}{m C_{p, m}} d \theta$ 


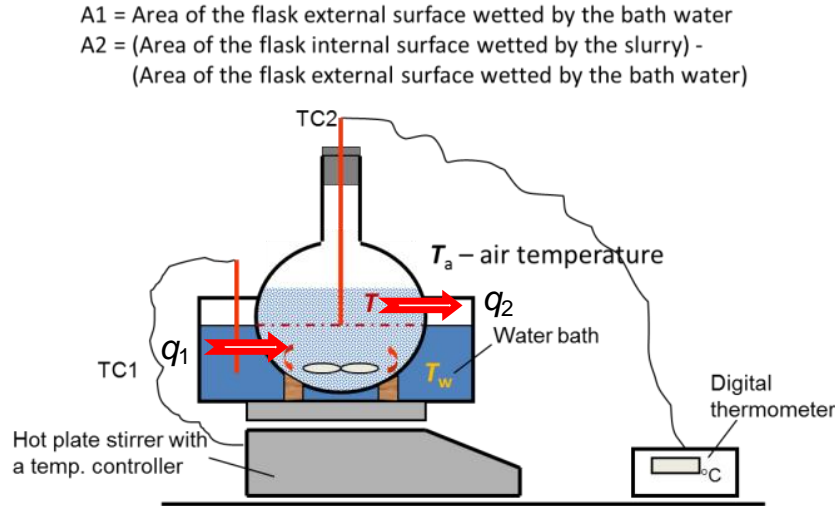

Fig. 1. Heat balance of the stirred tank reactor with a slurry of water-solid particles heated in a water bath at $T_{\mathrm{w}}$.

$\int_{T_{0}}^{T} \frac{d T}{\left(-A_{1} U_{1}-A_{2} U_{2}\right) T+A_{1} U_{1} T_{w}+A_{2} U_{2} T_{a}}=\int_{0}^{\theta} \frac{1}{m C_{p, m}} d \theta$

$\ln \frac{\left(-A_{1} U_{1}-A_{2} U_{2}\right) T+A_{1} U_{1} T_{w}+A_{2} U_{2} T_{a}}{\left(-A_{1} U_{1}-A_{2} U_{2}\right) T_{0}+A_{1} U_{1} T_{w}+A_{2} U_{2} T_{a}}=\frac{\left(-A_{1} U_{1}-A_{2} U_{2}\right)}{m C_{p, m}} \theta$

If plot $T$ vs. time $\theta$, we may obtain a plot like the following Figure:

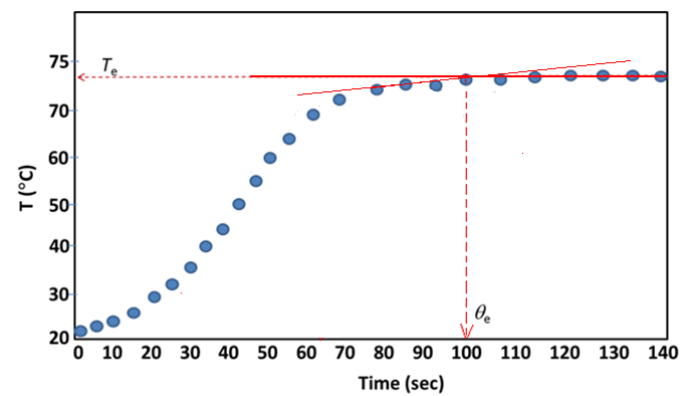

Fig. 2. Mock plot of $T$ vs. $\theta$ (note: actually measurement would be different)

From the above plot, we may read the equilibrium temperature $T_{\mathrm{e}}$ and the equilibrium time $\theta_{\mathrm{e}}$ when the temperature will remain approximately constant.

From Eq. (5), at $\theta=\theta_{\mathrm{e}}$, we have

$\ln \frac{\left(-A_{1} U_{1}-A_{2} U_{2}\right) T_{e}+A_{1} U_{1} T_{w}+A_{2} U_{2} T_{a}}{\left(-A_{1} U_{1}-A_{2} U_{2}\right) T_{0}+A_{1} U_{1} T_{w}+A_{2} U_{2} T_{a}}=\frac{\left(-A_{1} U_{1}-A_{2} U_{2}\right)}{m C_{p, m}} \theta_{e}$

In addition, when $\theta=\theta_{\mathrm{e}}, T=T_{\mathrm{e}}, \mathrm{d} T / \mathrm{d} \theta=0$, from Eq. (1),

$$
\begin{aligned}
& 0=A_{1} U_{1}\left(T_{w}-T_{e}\right)-A_{2} U_{2}\left(T-T_{a}\right) \quad \text { or } \\
& A_{1} U_{1}\left(T_{w}-T_{e}\right)=A_{2} U_{2}\left(T-T_{a}\right) \\
& U_{1}=\frac{A_{2} U_{2}\left(T-T_{a}\right)}{A_{1}\left(T_{w}-T_{e}\right)}
\end{aligned}
$$

Combining Eqs. (6) and (7), we can solve for $U_{1}$ and $U_{2}$.

\subsection{Project \#3: Liquid Phase Mass Transfer in a Gas-Liquid Stirred Reactor System}

2.3.1 Project Objectives. At the end of this project, students should be able to:

(1) Experimentally measure liquid-phase mass transfer coefficients in a stirred autoclave reactor operated under elevated pressure;

(2) Measure Henry's constant for gas in a liquid

(3) Study the effects of stirring speed, temperature and pressure on the mass transfer coefficients in the reactor.

2.3.2 Relevance and Significance. It has been a great challenge to reduce humanity's emissions of carbon dioxide - a greenhouse gas believed to cause global warming and the climate changes. To mitigate climate change, deep reductions in carbon dioxide $\left(\mathrm{CO}_{2}\right)$ emissions will be required in the coming decades. Given the extent of emissions reductions needed, now nearing 30 billion metric tons a year, to stabilize atmospheric $\mathrm{CO}_{2}$ concentrations and the inertia involved in shifting the world's primary energy sources from fossil fuels to other alternatives, carbon capture and storage (CCS) will likely constitute a substantial share of emissions reduction in the next half-century [7]. In contrast to conventional carbon capture systems for power plants and other large point sources, Joshuah et al. [7] reported a system to capture $\mathrm{CO}_{2}$ directly from ambient air using a $\mathrm{NaOH}$ spray-based contactor. Various scrubbing processes have been proposed to remove $\mathrm{CO}_{2}$ from air or flue gases. These usually involve absorbing $\mathrm{CO}_{2}$ with water alkaline solution of $\mathrm{NaOH}$ and $\mathrm{Na}_{2} \mathrm{CO}_{3}$ or $\mathrm{K}_{2} \mathrm{CO}_{3}$. The stoichiometric absorption reaction of $\mathrm{CO}_{2}$ with an alkaline $\mathrm{NaOH}$ solution is a gas liquid reaction, strongly exothermic (as shown below):

$2 \mathrm{NaOH}(\mathrm{aq})+\mathrm{CO}_{2}(\mathrm{~g}) \rightarrow \mathrm{Na}_{2} \mathrm{CO}_{3}(\mathrm{aq})+\mathrm{H}_{2} \mathrm{O}(\mathrm{l}) ; \Delta \mathrm{H}^{\circ}=$ $-109.4 \mathrm{~kJ} / \mathrm{mol}$.

Similar as many reaction systems, the rate of a gasliquid reaction of $\mathrm{CO}_{2}$ and absorption of $\mathrm{CO}_{2}$ in an alkali solution would be limited by the liquid-phase mass transfer resistance. As widely known, the rate of a chemical reaction may be promoted under elevated pressure simply by increasing the concentration of the reactants. Effects of pressure on the liquid-phase mass transfer coefficient $k_{\mathrm{L}}$ at the free gas-liquid interface and on the volumetric coefficient $k_{\mathrm{La}}$ at the gas-bubble-liquid interface in a stirred vessel were studied with various gas-liquid systems in the pressure range 2-100 atm using gases of hydrogen, helium, argon, carbon dioxide and nitrogen [8]. It was found that both $k_{\mathrm{L}}$ and $k_{\mathrm{La}}$ for these 
gas-liquid systems remain constant with increasing pressure.

In this project, we aim to design experiments to (1) measure liquid-phase mass transfer coefficients and Henry's constant for $\mathrm{CO}_{2}$ in a stirred autoclave reactor operated under elevated pressure, and (2) investigate the effects of stirring speed, temperature and pressure on the mass transfer coefficients in the reactor

2.1.3 Theory/Background. From thermodynamics, a pressurized gas would deviate greatly from the ideal gas law, and its compressibility factor $(\mathrm{Z})$ can be calculated by the Pitzer the $2^{\text {nd }}$ Virial Coefficient method.

$Z=1+B^{o} \frac{P_{r}}{T_{r}}+\omega B^{1} \frac{P_{r}}{T_{r}}$

$B^{o}=0.083-\frac{0.422}{T_{r}^{1.6}}, B^{1}=0.139-\frac{0.172}{T_{r}^{4.2}}$

Where: $T_{r}=\frac{T}{T_{c}}, P_{r}=\frac{P}{P_{c}}$.

For $\mathrm{CO}_{2}, \omega=0.225, T_{\mathrm{c}}=304.19 \mathrm{~K}$ and $P_{\mathrm{c}}=73.8$ bar [9].

Assuming the pressure reactor has a total volume of

$V_{\mathrm{T}}$, it is loaded liquid at a volume of $V_{\mathrm{L}}$. As such, the gas volume $\left(V_{\mathrm{G}}\right)$ is estimated by $V_{\mathrm{G}}=V_{\mathrm{T}}-V_{\mathrm{L}} . V_{\mathrm{G}}$ and $V_{\mathrm{L}}$ may be assumed constant if the pressure and temperature of the reactor system are not extremely high. Suppose initially the reactor with $V_{\mathrm{L}}$ of $1 \% \mathrm{NaOH}$ solution is under atmospheric pressure of air ( 0 bar gauge pressure). The sealed reactor is heated up to the specified temperature without stirring, say, $T(\mathrm{~K})$, when the reactor gauge pressure increases negligibly to $P_{\mathrm{T}, 0}$ $\left(\approx 0\right.$ bar). If pressurize the reactor to rapidly $P_{\mathrm{T}, 0}^{\mathrm{t}}$ with pure $\mathrm{CO}_{2}$ and assuming negligible $\mathrm{CO}_{2}$ absorption by the liquid phase (due to a very short time period of the pressurization operation), we have the initial pressure of $\mathrm{CO}_{2}$ in the gas phase is approximately: $P_{\mathrm{G}, 0}=P_{\mathrm{T}, 0}^{\mathrm{t}}-P_{\mathrm{T}, 0}$ $\approx P_{\mathrm{T}, 0}^{\mathrm{t}}$

The initial molar number of the $\mathrm{CO}_{2}$ charged into the reactor can be calculated as: $n_{T}=\frac{P_{G, 0} V_{G}}{z R T}$.

Start the agitation of the reactor by a controlled stirring speed (rpm), and record the reactor gauge pressure $(P)$ vs. time $(\theta)$. After starting the agitation, $\mathrm{CO}_{2}$ will be transferred from the gas phase into the alkaline solution. Therefore the gauge pressure of the reactor will drop continuously, until the equilibrium or saturated pressure $\left(P^{\mathrm{s}}\right)$ is reached, when the reactor pressure does not decrease anymore, the saturated pressure $P^{\mathrm{s}}$ is reached and the $\mathrm{CO}_{2}$ saturated concentration in the liquid phase is $C_{\mathrm{s}}$.

$C_{\mathrm{s}}$ can be calculated by the following equation:

$C_{s}=\frac{n_{L}^{S}}{V_{L}}=\frac{n_{T}-n_{G}^{S}}{V_{L}}=\frac{n_{T}-\frac{P^{S} V_{G}}{z R T}}{V_{L}}$
Similarly, the $\mathrm{CO}_{2}$ concentration in the liquid phase, $C_{\mathrm{L}}$, at pressure of $P$ is:

$C_{L}=\frac{n_{L}}{V_{L}}=\frac{n_{T}-n_{G}}{V_{L}}=\frac{n_{T}-\frac{P V_{G}}{z R T}}{V_{L}}$

From the definition of the overall liquid-phase mass transfer coefficients, $k_{\mathrm{La}}$ :

$$
\begin{aligned}
& \frac{d C_{L}}{d \theta}=k_{L a}\left(C_{s}-C_{L}\right) \\
& \frac{d C_{L}}{C_{s}-C_{L}}=k_{L a} d \theta \\
& -\frac{d\left(C_{s}-C_{L}\right)}{C_{s}-C_{L}}=k_{L a} d \theta \\
& -\int_{C_{0}}^{C_{L}} \frac{d\left(C_{s}-C_{L}\right)}{C_{s}-C_{L}}=\int_{0}^{\theta} k_{L a} d \theta \\
& -\ln \frac{C_{s}-C_{L}}{C_{s}-C_{0}}=k_{L a} \theta \text { or } \\
& \ln \frac{C_{s}-C_{0}}{C_{s}-C_{L}}=k_{L a} \theta
\end{aligned}
$$

For simplicity, we may assume $C_{0} \approx 0 \mathrm{~mol} / \mathrm{m}^{3}$ (i.e., the initial $\mathrm{CO}_{2}$ concentration in the liquid phase is $0 \mathrm{~mol} / \mathrm{m}^{3}$ at $\theta=0 \mathrm{sec}$ )

Thus,

$\ln \frac{C_{s}}{C_{s}-C_{L}}=k_{L a} \theta$

If plot $\ln \frac{C_{s}}{C_{s}-C_{L}}$ vs. $\theta$, a linear line will be obtained, and the slope of the line is $k_{\mathrm{La}}$.

We can also calculate the Henry's constant, $\mathbf{H}$ (Pa.m $\mathrm{m}^{3} / \mathrm{mol}$ or atm.L/mol, or psi. $\mathrm{m}^{3} / \mathrm{mol}$ ) for $\mathrm{CO}_{2}$ at the equilibrium/saturated condition:

$$
P^{S}=C_{s} H \text {, or } H=P^{S} / C_{s}
$$

\subsection{Project \#4: A Green Process for the Production of Acetic Acid via Aqueous Phase Oxidation of Ethanol with Air using $\mathrm{Au} / \mathrm{MgAl}_{2} \mathrm{O}_{4}$ Catalyst: Effects of Mass Transfer and Reaction Kinetics}

2.4.1 Project Objectives. At the end of this project, students should be able to:

(1) Investigate on an alternative green process for the production of acetic acid via aqueous phase oxidation of ethanol with air using $\mathrm{Au} / \mathrm{MgAl}_{2} \mathrm{O}_{4}$ catalyst;

(2) Study the effects of temperature and mass transfer (stirring speed) on the ethanol conversion and acetic acid product yield. 
2.4.2 Relevance and Significance. Acetic acid is currently produced by the following routes: fermentation (vinegar), catalytic liquid-phase oxidation of butane, naphtha, or acetaldehyde, and the carbonylation of methanol. As a greener process (using renewable feedstock, and catalyst), acetic acid can be produced by oxidation of bioethanol:

$$
\begin{gathered}
\mathrm{CH}_{3} \mathrm{CH}_{2} \mathrm{OH}+\mathrm{O}_{2} \rightarrow \mathrm{CH}_{3} \mathrm{COOH}+\mathrm{H}_{2} \mathrm{O} \\
\Delta \mathrm{H}_{298}^{\circ}=-448.6 \mathrm{~kJ} / \mathrm{mol}
\end{gathered}
$$

The oxidation of ethanol by air into acetic acid over platinum was among the first heterogeneously catalyzed reactions to be reported. The initial discovery was made by D. Bereiner about two centuries ago [10]. Today, bio-ethanol can also be produced from cellulose-rich agricultural forestry waste, so the route via ethanol oxidation will not only be a greener route, but also an economically viable technology for acetic acid production. It is possible to selectively oxidize ethanol into acetic acid in aqueous solution using air as the oxidant with a heterogeneous gold catalyst at temperatures of about $423 \mathrm{~K}$ and $\mathrm{O}_{2}$ pressures of 0.6 MPa. This reaction proceeds readily in aqueous media using a heterogeneous catalyst: $1 \mathrm{wt} \% \mathrm{Au} / \mathrm{MgAl}_{2} \mathrm{O}_{4}, \mathrm{Pd} /$ $\mathrm{MgAl}_{2} \mathrm{O}_{4}$ or $\mathrm{Pt} / \mathrm{MgAl}_{2} \mathrm{O}_{4}$, and up to $90 \%$ acetic acid yield were achieved, with $\mathrm{CO}_{2}$ as the only major byproduct [10]. Thus, it constitutes a very simple and, green process for acetic acid production.

This project aims to investigate on an alternative green process for the production of acetic acid via aqueous phase oxidation of ethanol with air using the $1 \mathrm{wt} \% \mathrm{Au} / \mathrm{MgAl}_{2} \mathrm{O}_{4}$ catalyst prepared in Project \#1, and study the effects of temperature and mass transfer (stirring speed) on the ethanol conversion and acetic acid product yield.

2.4.3 Requirements on the experimental proposal. Referring to the literature work of ref. [10], students are required to propose detailed procedure for a typical reaction run, including the following sections:

- Reactor feed composition (suggested composition: $20 \pm 0.01$ gram 5\% aqueous ethanol solution);

- Reaction conditions (suggested conditions: 4.0 $\mathrm{MPa}$ Air; 0.5g 1wt\% Au/Mg Al${ }_{2} \mathrm{O}_{4}$ Catalyst, and $\left.100-200^{\circ} \mathrm{C}\right)$

- Reactor operation;

- Product separation methods and procedure (Note: In this project, students are only required to separate the liquid products from the spent catalyst and recover both for analysis. The gas products will not be collected and analyzed, and it will be vented to the fume hood after each experiment);

- HPLC method for the liquid product analysis and ethanol conversion and yield of acetic acid calculation.
- Propose a research plan to investigate the effects of temperature and mass transfer (stirring speed) on the ethanol conversion and acetic acid product yield.

\section{EQUIPMENT AND MATERIALS}

\subsection{Equipment and Materials for Project \#1}

\begin{tabular}{|c|}
\hline Item specifications \\
\hline Hot plate stirrer \\
\hline Centrifuge \\
\hline Drying oven \\
\hline Muffle furnace \\
\hline $1000 \mathrm{~mL}$ beaker \\
\hline Mortar/pestle set \\
\hline Sieve set \\
\hline Magnesium nitrate hexahydrate: $\mathrm{Mg}\left(\mathrm{NO}_{3}\right)_{2} \cdot 6 \mathrm{H}_{2} \mathrm{O}$ \\
\hline Aluminum nitrate nonahydrate: $\mathrm{Al}\left(\mathrm{NO}_{3}\right)_{3} \cdot 9 \mathrm{H}_{2} \mathrm{O}$ \\
\hline Ammonium hydroxide solution \\
\hline Gold(III) chloride trihydrate \\
\hline
\end{tabular}

Table 2: Equipment and materials for Project \#1.

\subsection{Equipment and Materials for Project \#2}

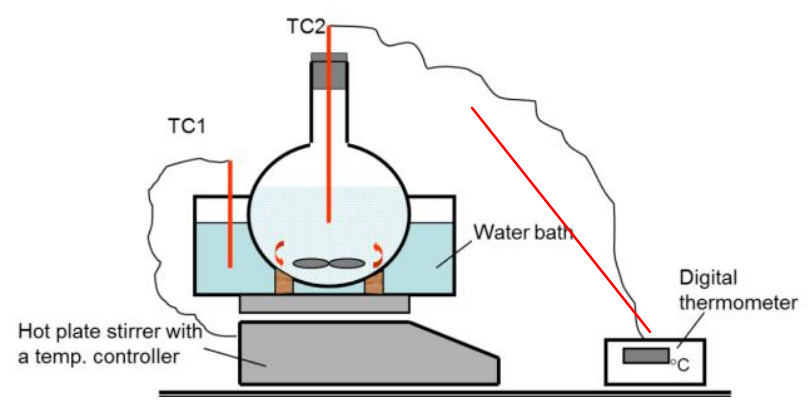

Fig. 3. Stirred tank reactor system for heat transfer studies

Table 3. Equipment and materials for Project \#2.

\begin{tabular}{|l|}
\hline Item specifications \\
\hline Water bath \\
\hline Hot Plate Stirrer with Temperature Control Package, $7{ }^{\prime \prime} \times 7^{\prime \prime}$ \\
\hline PYREX® round bottom boiling flasks, Short Neck, $1 \mathrm{~L}$ \\
\hline VWR® Digital Thermometer/Timer with Alarm \\
\hline Glass beads of $40 \mu \mathrm{m}$ diameter, $C_{p}=1.23 \mathrm{~J} / \mathrm{g} / \mathrm{K}$ \\
\hline Distilled water \\
\hline
\end{tabular}

\subsection{Equipment and Materials for Project \#3}

Table 4: Equipment and materials for Project \#3.

\begin{tabular}{|l|}
\hline Item name/specifications \\
\hline $\mathrm{Parr}_{2}$ stirred autoclave reactor $100 \mathrm{~mL}^{*}$ \\
\hline $\mathrm{CO}_{2}$ pressure regulator, 50-700 psig \\
\hline Druck Digital Test Gauge, Range 1000 psia. \\
Eleven Selectable pressure units, Accuracy +/- $0.05 \% \mathrm{FS}$ \\
$\mathrm{C} / \mathrm{w}$ Calibration Certificate traceable to NIST \\
\hline $\mathrm{PC}$ serial Interface Lead, Part\# IA-4090-2-V-0, C/w RS232 \\
to USB dongle \\
\hline $\mathrm{CO}_{2}$ gas cylinder \\
\hline Data logger Software for Druck DPI 104 \\
\hline
\end{tabular}




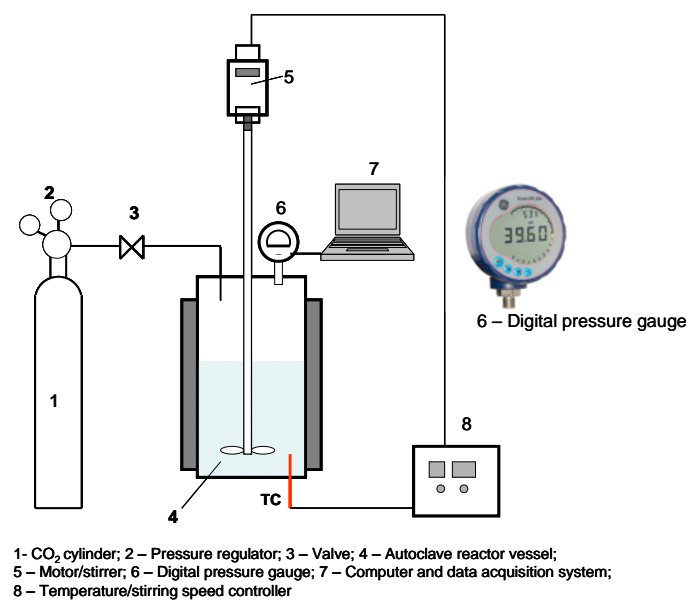

Fig. 4. Stirred autoclave reactor system for gas-liquid mass transfer studies. Note: The pressure in the vessel is measured with the digital test gauge (GE DPI 104) and the data is recorded manually or with a laptop computer using the GE SiCalPro Monitor and control software.

\subsection{Equipment and Materials for Project \#4}

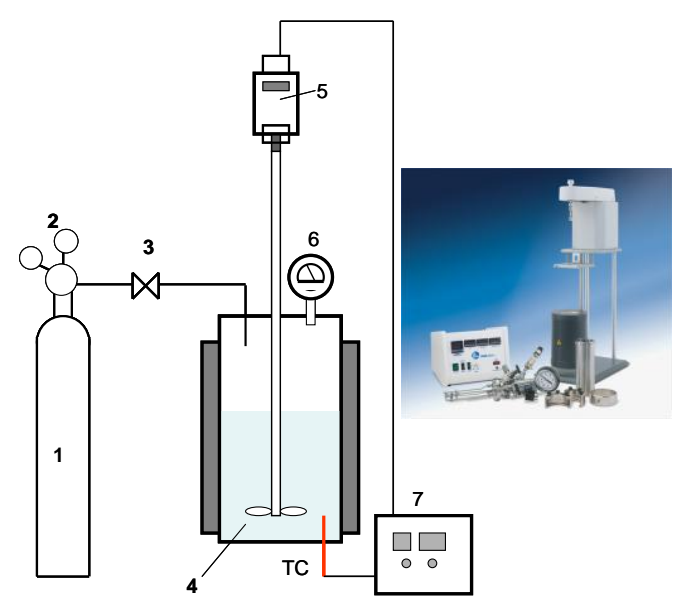

1- Air cylinder; 2 - Pressure regulator; 3 - Valve; 4 - Autoclave reactor vessel with heterogeneous catalyst particles loaded; 5 - Motor/stirrer; 6 -Pressure gauge; 7 - Temperature/stiring speed controller

Fig. 5. Autoclave reactor system for the production of acetic acid via aqueous phase oxidation of ethanol with air using $1 \mathrm{wt} \%$ $\mathrm{Au} / \mathrm{MgAl}_{2} \mathrm{O}_{4}$ catalyst

Table 5 Equipment and materials for Project \#3

\begin{tabular}{|l|}
\hline Item name/specifications \\
\hline Parr stirred autoclave reactor $100 \mathrm{~mL}$ \\
\hline $\mathrm{HPLC}$ \\
\hline Centrifuge \\
\hline Air pressure regulator, delivery pressure $50-700 \mathrm{psig}$ \\
\hline Air gas cylinder \\
\hline $1 \mathrm{wt} \% \mathrm{Au} / \mathrm{MgAl}_{2} \mathrm{O}_{4}$ catalyst $(<300 \mu \mathrm{m})$ \\
\hline
\end{tabular}

Some key results from each project are briefly presented and discussed as follows.

\subsection{Project \# 1}

For almost all groups, approx. $4.5 \mathrm{~g} 1 \mathrm{wt} \% \mathrm{Au} / \mathrm{MgAl}_{2} \mathrm{O}_{4}$ calcinated particles were obtained. Comparing with the target amount $(5 \mathrm{~g})$, the $10 \%$ mass loss was reasonable, due to the unavoidable loss in the various operation steps (impregnation, centrifugal separation, drying and calcination, etc.). The textual structure and chemical composition of the catalyst were characterized by nitrogen isothermal adsorption (77K) and SEM/EDX, respectively. The results are summarized in Tables 6 and 7 , respectively.

Table 6 BET specific surface area and pore size distribution of the obtained $1 \mathrm{wt} \% \mathrm{Au} / \mathrm{MgAl}_{2} \mathrm{O}_{4}$ particles

\begin{tabular}{|l|l|}
\hline BET specific surface area $\left(\mathrm{m}^{2} / \mathrm{g}\right)$ & $32.2 \pm 1.2$ \\
\hline Langmuir Surface Area $\left(\mathrm{m}^{2} / \mathrm{g}\right)$ & 41.7 \\
\hline $\begin{array}{l}\text { BJH Desorption Cumulative Pore } \\
\begin{array}{l}\text { Volume of pores } \\
\text { between 1.7- 300nm Diameter }\left(\mathrm{cm}^{3} / \mathrm{g}\right)\end{array}\end{array}$ & 0.32 \\
\hline $\begin{array}{l}\text { BJH Desorption Average Pore } \\
\text { Diameter }(\mathrm{nm})\end{array}$ & 15.4 \\
\hline
\end{tabular}

Table 7 SEM/EDX results for $1 \mathrm{wt} \% \mathrm{Au} / \mathrm{MgAl}_{2} \mathrm{O}_{4}$ particles

\begin{tabular}{|l|l|l|}
\hline SEM image & \multicolumn{2}{|c|}{} \\
& & \\
& & \\
& & \\
& & \\
& & 20 um \\
& & $\begin{array}{l}\text { Theoretical } \\
\text { (wt \%) }\end{array}$ \\
\hline EDX results & $\begin{array}{l}\text { Measurement } \\
\text { (wt \%) }\end{array}$ & 45.1 \\
\hline Oxygen (O) & 43.9 & 38.0 \\
\hline Aluminum (Al) & 46.7 & 16.9 \\
\hline Magnesium (Mg) & 7.7 & 1.0 \\
\hline Gold (Au) & 1.5 & \\
\hline
\end{tabular}

XRD measurement was performed to indentify the crystalline structure of the fresh 1 wt $\% \mathrm{Au} / \mathrm{MgAl}_{2} \mathrm{O}_{4}$ catalyst, and the XRD pattern is illustrated in Fig. 6. The dominant species identified in the catalyst are spinel $\left(\mathrm{MgAl}_{2} \mathrm{O}_{4}\right)$, with some weak signals of $\mathrm{Al}_{2} \mathrm{O}_{3}$, as expected. The gold-containing species were not detected due to the XRD detection limit (> $5 \mathrm{wt} \%$ ). The XRD results, along with the EDX results, further prove the success of synthesis of $\mathrm{MgAl}_{2} \mathrm{O}_{4}$ particulate materials in Project \#1.

\section{RESULTS \& DISCUSSION}




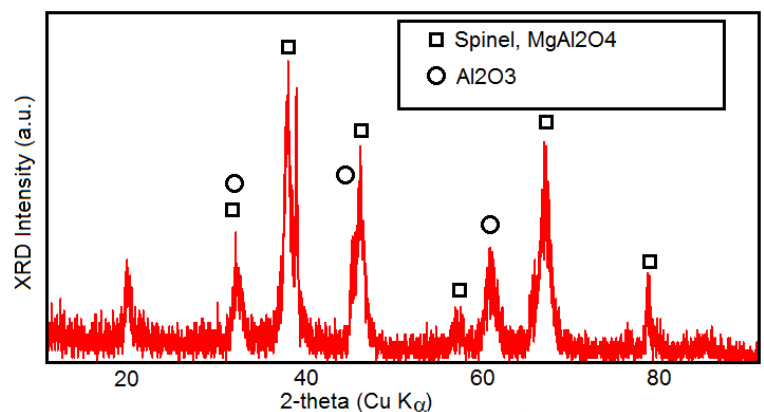

Fig. 6. XRD pattern of the fresh $1 \mathrm{wt} \% \mathrm{Au} / \mathrm{MgAl}_{2} \mathrm{O}_{4}$ catalyst

\subsection{Project \# 2}

Effects of reactor stirring speed and glass beads addition amount on the global heat transfer coefficients $U_{1}$ and $\mathrm{U}_{2}$ are shown in Figs. 7 and $8 . \mathrm{U}_{1}$ is the global heat transfer efficiency on the surface of $A_{1}$ and $U_{2}$ is the global heat transfer efficiency on the surface of $\mathrm{A}_{2}$, as shown in Fig. 1. Under the stirred condition, $U_{1}$ is mainly determined by the combination of forced convection and conduction. In contrast, $\mathrm{U}_{2}$ is mainly attributed to the natural convective heat transfer between the reactor and the air environment. From Figs. 7 and 8, it is clear that under all circumstance, $\mathrm{U}_{1} \gg \mathrm{U}_{2}$. From Fig. 7, an increase in reactor stirring speed consistently reduces the value of $U_{2}$, which might be caused by the increased heat loss from the reactor top surface (which was not taken into account in the heat balance equation). Interestingly, the stirring speed has mixed effects on the $\mathrm{U}_{1}$, increasing reactor stirring speed up to $100-200 \mathrm{rpm}$ increases $U_{1}$ due to enhanced convective heat transfer as expected. However, if further increasing the stirring speed, the value of $U_{1}$ reduces, which might be due to generation of some air bubbles in the reactor, retarding the heat transfer inside the reactor. From Fig. 8, the addition of glass beads consistently decreased $U_{1}$ while in the opposite increased $\mathrm{U}_{2}$. The drop in $\mathrm{U}_{1}$ is actually predictable since the heat capacity of glass beads $\left(C_{\mathrm{p}}=\right.$ $\left.0.84 \mathrm{~J} / \mathrm{g} /{ }^{\circ} \mathrm{C}\right)$ is much lower than water $\left(C_{\mathrm{p}}=4.184\right.$ $\left.\mathrm{J} / \mathrm{g} /{ }^{\circ} \mathrm{C}\right)$. The addition of glass beads caused a decrease in the overall heat capacity of the mixture, hence resulted in reduced $\mathrm{U}_{1}$.

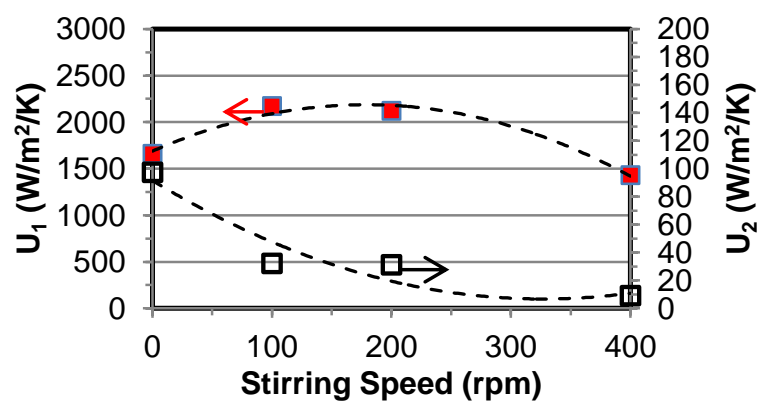

Fig. 7. Global heat transfer coefficients $U_{1}$ and $U_{2}$ vs. reactor stirring speed (other conditions are: water heating bath temperature $T_{\mathrm{w}}=60^{\circ} \mathrm{C}$, air temperature $T_{\mathrm{a}}=20^{\circ} \mathrm{C}$, glass beads addition $=0 \mathrm{~g}, 700 \mathrm{~g}$ water in the reactor)

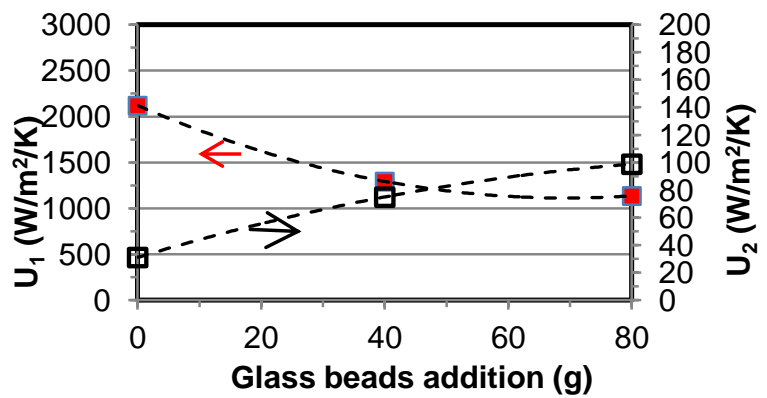

Fig. 8. Global heat transfer coefficients $U_{1}$ and $U_{2}$ vs. glass beads addition (other conditions are: water heating bath temperature $T_{\mathrm{w}}=60^{\circ} \mathrm{C}$, air temperature $T_{\mathrm{a}}=20^{\circ} \mathrm{C}$, reactor stirring speed $=200 \mathrm{rpm}, 700 \mathrm{~g}$ water in the reactor)

\subsection{Project \# 3}

Dependency of liquid-phase mass transfer coefficients, $k_{\mathrm{La}}$, and Henry's Constant $(H)$ are shown in Table 8. A general conclusion from the mass transfer research results is that liquid-phase mass transfer coefficient and Henry's constant both increase with increasing stirring speed, raising reactor temperature, or operating at a higher $\mathrm{CO}_{2}$ initial pressure.

Table 8. $k_{\mathrm{La}}$, and $H$ vs. stirring speed, reactor temperature and $\mathrm{CO}_{2}$ initial pressure.

\begin{tabular}{|c|c|c|c|c|}
\hline $\begin{array}{l}\text { Stirring } \\
\text { Speed } \\
\text { (rpm) }\end{array}$ & $\begin{array}{l}\text { Reactor } \\
\text { Temp. } \\
\left({ }^{\circ} \mathrm{C}\right)\end{array}$ & $\begin{array}{l}\mathrm{CO}_{2} \text { initial } \\
\text { Press. (psi) }\end{array}$ & $\begin{array}{c}k_{\mathrm{La}} \\
\left(\min ^{-1}\right)\end{array}$ & $\underset{\left(\text { psi. } \mathrm{m}^{3} / \mathrm{mol}\right)}{\boldsymbol{H}}$ \\
\hline 0 & 60 & 100 & 0.025 & 6033 \\
\hline 400 & 60 & 100 & 0.082 & 8008 \\
\hline 200 & 30 & 100 & 0.031 & 2598 \\
\hline 200 & 90 & 100 & 0.105 & 5367 \\
\hline 200 & 60 & 300 & 0.048 & 1638 \\
\hline 200 & 60 & 500 & 0.056 & 6176 \\
\hline
\end{tabular}

\subsection{Project \# 4}

In this project, acetic acid was successfully produced via a green process (by oxidation of bioethanol with air and the $1 \mathrm{wt} \% \mathrm{Au} / \mathrm{MgAl}_{2} \mathrm{O}_{4}$ catalyst produced from Project \#1, via the following reaction:

$$
\begin{gathered}
\mathrm{CH}_{3} \mathrm{CH}_{2} \mathrm{OH}+\mathrm{O}_{2} \rightarrow \mathrm{CH}_{3} \mathrm{COOH}+\mathrm{H}_{2} \mathrm{O} \\
\Delta \mathrm{H}_{298}^{\circ}=-448.6 \mathrm{~kJ} / \mathrm{mol}
\end{gathered}
$$

The acetic acid yield was found strongly dependent on the reaction conditions (reactor temperature, stirring speed). The experimental results from various tests are summarized in Table 9. As shown in the Table, 
generally a higher reaction or a larger stirring speed led to a higher product yield. However the results from Runs 4 and 6 seem to be questionable, which might due to experimental errors or some unexpected mistakes during the tests. Replicate tests are needed to prove these results. The yield of the control tests (Runs 1 and 2) produced an acetic acid yield of $14.4-20.5 \%$, which is in a good agreement of the literature results reported by Christensen et al. [10].

Table 9. Acetic acid yields in various runs under different conditions (Other process conditions: $20 \pm 0.01 \mathrm{gram} 5 \%$ aqueous ethanol solution, 4.0 MPa Air, 0.5g 1wt\% Au/Mg Al $\mathrm{O}_{4}$ catalyst, and $2 \mathrm{~h}$ reaction).

\begin{tabular}{cccc}
\hline Run & $\begin{array}{c}\text { Reactor } \\
\text { Temp. }\left({ }^{\circ} \mathbf{C}\right)\end{array}$ & $\begin{array}{c}\text { Stirring } \\
\text { Speed } \\
\text { (RPM) }\end{array}$ & $\begin{array}{c}\% \\
\text { Yield }\end{array}$ \\
\hline Control Run 1 & 150 & 156.19 & 20.5 \\
Control Run 2 & 150 & 156.19 & 14.4 \\
Run 3 & 100 & 156.19 & 8.1 \\
Run 4* & 200 & 156.19 & 1.9 \\
Run 5 & 150 & 0 & 0 \\
Run 6* & 150 & 369.5 & 3.9 \\
\hline $\begin{array}{l}\text { *These results seem to be questionable, which might due to } \\
\text { experimental errors or some unexpected mistakes during the } \\
\text { tests. Replicate tests are needed to prove these results. }\end{array}$
\end{tabular}

\section{CONCLUDING REMARKS}

An innovative undergraduate laboratory course (GPE3395Y) have been developed and delivered since September 2011 to the Green Process Engineering program at Western University. This course integrates laboratories for different courses of the green process engineering curriculum, including particulate operations, and heat/mass transfer as well as chemical reaction engineering. The integrated lab course runs as integrated research projects that apply and integrate the concepts reviewed in the above courses. This course proved to be effective for training team work and leadership for the class. In this course, students propose their own experimental methodologies and design their experimental procedure, secure and prepare their experimental materials, equipment and facilities, perform the experiments and collect data, interpret the experimental results using the principles and knowledge from the relevant courses, and present their results effectively. All students highly rate this course for the active learning experience they attain from this lab course, differing from the passive learning experience from other conventional lab courses.

\section{Acknowledgements}

The authors want to cordially acknowledge the strong support from Prof. Ajay Ray (chair of Department of Chemical and Biochemical Engineering of Western) to the development and delivery of this new lab course, offering financial and space supports. The authors are also very grateful for the technical assistance from Lab Technicians of the CBE department, i.e., Mr. Souheil Afara and Mr. Brian Dennis. Special thanks also go to Instrumentation Technician, Dr. Ying Zhang at CBE department, and Dr. Sean Yuan at Institute for Chemicals and Fuels from Alternative Resources (ICFAR) for the great assistance and help in HPLC analysis for Project \#4.

\section{References}

[1] http://www.eng.uwo.ca/chemical/GreenProcess.htm

[2] http://www.theinfoshop.com/study/bc21724_energy_applications.html.

[3] J. Salmones, J. A. Galicia, J. A. Wang, M. A. Valenzuela and G. Agilar-rios, "Synthesis and characterization of nanocrystallite $\mathrm{MgAl}_{2} \mathrm{O}_{4}$ spinels as catalysts support", Journal of Materials Science Letter, vol. 19, pp. 1033 1037, 2000.

[4] Ji-Guang Li, Takayasu Ikegami, Jong-Heun Lee, Toshiyuki Mori, Yoshiyuki Yajima, "Synthesis of $\mathrm{Mg} \pm \mathrm{Al}$ spinel powder via precipitation using ammonium bicarbonate as the precipitant", Journal of the European Ceramic Society, vol. 21, pp. 139-148, 2001.

[5] Surbhi Semwala, Ajay K. Arorab, Rajendra P. Badonia, Deepak K. Tulib, "Biodiesel production using heterogeneous catalysts", Bioresource Technology, vol. 102, no. 3, pp. 2151-2161, February 2011.

[6] Susanne Retka Schill, http://www.biodieselmagazine.com/articles/3536/a-solidcatalyst-unlike-the-rest, June 09, 2009.

[7] Joshuah K. Stolaroff, David W. Keith, Gregory V., "Lowry. Carbon Dioxide Capture from Atmospheric Air Using Sodium Hydroxide Spray", Environ. Sci. Technol., vol. 42, pp. 2728-2735, 2008.

[8] M. TERAMOTO, S. TAI, K. NISHII and H. TERANISHI, "Effects of Pressure on Liquid-Phase Mass Transfer Coefficients", The Chemical Engineering Journal, vol. 8, pp. 223-226, 1974

[9] J.M. Smith, H.C. Van Ness, M.M.Abbott, "Introduction to Chemical Engineering Thermodynamics" ( $7^{\text {th }}$ edition), McGraw-Hill's, Boston, 2005.

[10] C.H. Christensen, B. Jørgensen, J. Rass-Hansen, K. Egeblad, R. Madsen, S.K. Klitgaard, S.M. Hansen, M.R. Hansen, H.C. Andersen, A. Riisager, "Formation of Acetic Acid by Aqueous-Phase Oxidation of Ethanol with Air in the Presence of a Heterogeneous Gold Catalyst", Angew. Chem. Int. Ed. Vol. 45, pp. 4648 -4651, 2006. 